\section{Extremely large hemangioma of the liver: Safety of the expectant management}

\author{
Subhi Mansour ${ }^{1}$, Sharbel Khouri ${ }^{2}$, Maisa Andraous ${ }^{3}$ and Safi \\ Khuri ${ }^{1,4 *}$ \\ ${ }^{1}$ Department of General Surgery, Rambam Health Care Campus, Haifa, Israel \\ ${ }^{2}$ Department of Radiology, Galilee Medical Center, Nahareya, Israel \\ ${ }^{3}$ Department of Radiology, Rambam Health Care Campus, Haifa, Israel \\ ${ }^{4} \mathrm{HPB}$ and Surgical Oncology Unit, Rambam Health Care Campus, Haifa, Israel
}

\section{Abstract}

Hemangiomas are known as congenital vascular malformations that can affect almost any organ or tissue, with the liver being the most common intra-abdominal organ to be involved. It is well known that hemangiomas are the most common benign tumours of the liver, and develop in about $4-20 \%$ of people, mainly young adult females. Recently, due to the dramatic rise in the use of imaging studies for different purposes, a parallel increase in the incidence of these tumours has been noticed. Most liver hemangiomas are small (less than $4 \mathrm{~cm}$ in diameter), asymptomatic and found incidentally during abdominal operation for other indication or on radiologic studies. Giant liver hemangioma is defined as hemangioma with a diameter of more than $5 \mathrm{~cm}$. This unique and uncommon type of haemangioma usually poses therapeutic challenges for the treating physician, especially hepatic surgeons, due to the unclear natural history, and due to the risk of life threatening complications is yet to be established. While it is already proved by several studies that conservative management of giant hepatic hemangioma is safe, it is not known whether observation of the extremely large hepatic hemangioma (tumours larger than $10 \mathrm{~cm}$ ) is safe as well.

The aim of this article is to review the English literature to find out if conservative management of the extremely giant liver hemangioma is safe and can be recommended.

\section{More Information}

*Address for Correspondence: Safi Khuri, Department of Surgery, HPB and Surgical Oncology Unit, Rambam Health Care Campus, Haifa, Israel, Tel: 00972502062169; Email: s_khuri@rambam.health.gov.il

Submitted: 26 August 2019

Approved: 05 September 2019

Published: 06 September 2019

How to cite this article: Mansour S, Khouri S, Andraous M, Khuri S. Extremely large hemangioma of the liver: Safety of the expectant management. Arch Surg Clin Res. 2019; 3: 061-064.

DOI: dx.doi.org/10.29328/journal.ascr.1001036

Copyright: (c) 2019 Mansour S, et al. This is an open access article distributed under the Creative Commons Attribution License, which permits unrestricted use, distribution, and reproduction in any medium, provided the original work is properly cited

Keywords: Extremely large hepatic hemangioma; Conservative management

Check for updates

\section{Introduction}

Hemangiomas are well known congenital vascular malformations, and sometimes are referred to as cavernous hemangiomasorcavernomas. Althoughgenetic predisposition has been proposed, the exact aetiology for this tumour is still unknown. These lesions can affect any organ site of the body, with the scalp and face being the most commonly affected sites [1]. Hemagiomas, a benign tumour that enlarge by ectasia rather than hypertrophy or hyperplasia, can vary in size from few millimetres to several centimetres in diameter [2]. The current evidence indicates that these tumours have no malignant potential. Intraabdominally, hemangioma can develop anywhere, such as solid organs, ligaments, hollow viscera or in the abdominal wall, with the liver being the most common abdominal organ to be involved [1]. Of all tumours affecting the liver, hemangioma is the second most common following metastasis and the most common benign mesenchymal tumour. Although its precise incidence is unknown, it is estimated to affect about $4-20 \%$ of the general population [3]. Recently, due to the dramatic increase in the number of people undergoing different radiologic imaging techniques, a parallel rise in the incidence of this tumour has been noticed [4]. Hepatic hemangiomas can affect any age group, with young adult females being the most common group to have this tumour (F:M ratio 5:1) [5]. Most of the tumours are detected between the third and the fifth decade of life. Macroscopically, these tumours are hypervascular, well- circumscribed lesions; while microscopically, they are described as variably sized vascular spaces lined by flat endothelial cells, filled with ectatic blood and separated by fibrous septa. Different types of hepatic hemangiomas were reported, with the cavernous subtype being the most common and constitute about $80 \%$, while the papillary subtype is less common and is characterized by being usually smaller with multiple growths. Giant hemangioma has always been defined as tumour larger than $5 \mathrm{~cm}$ diameter, but recently, new classification for these tumours according to size has been advocated; Small hemangiomas are tumours 
with a diameter of 1-2cm, typical hemangiomas are $2 \mathrm{~cm}-10$ $\mathrm{cm}$ in diameter and giant hemangiomas are larger than $10 \mathrm{~cm}$ $[6,7]$. Most physicians still define giant liver hemangioma as a lesions larger than $5 \mathrm{~cm}$.

Most hepatic hemangiomas are small (less than $4 \mathrm{~cm}$ in diameter) and asymptomatic, and diagnosed incidentally either by imaging studies or during abdominal operations done for other surgical indications (Figure 1). For the majority of people who are known to have liver hemangioma, the natural history remains uneventful, with observations by means of regular follow ups and radiologic studies being adequate $[8,9]$. While almost all small asymptomatic hemangiomas are safely observed, the unclear natural history and the possibility of future complications for giant haemangioma, especially tumours larger than $10 \mathrm{~cm}$ in diameter, makes management of this specific type of tumour a controversial issue for the treating physician [10]. Indications for surgical interventions include diagnostic uncertainty, spontaneous or traumatic rupture, rapid lesion growth, consumptive coagulopathy (Kasabach-Merrit syndrome) and severe symptoms - mainly severe abdominal pain due to giant lesions causing stretching of the Glisson capsule of the liver [11-13].

\section{Objective}

The review article was performed to explore the different relevant studies in the English literature to figure out if conservative management of the extremely giant liver haemangiomas, larger than $10 \mathrm{~cm}$, by wait and see strategy is safe and can be routinely recommended.

\section{Methods}

A search of studies was conducted on PubMed. A term strategy based on PICOS acronym was adopted, using subjects heading and text words that allow to identify studies including patients with extremely large hepatic haemangioma (larger than $10 \mathrm{~cm}$ ), who were assigned for conservative vs. non-conservative treatment.

The following search strategy was used on the PubMed database including the following search terms: "hepatic haemangioma" "haemangioma of the liver", "giant liver haemangioma", "conservative management of giant hepatic haemangioma", giant haemangioma of the liver: conservative vs. surgical management".

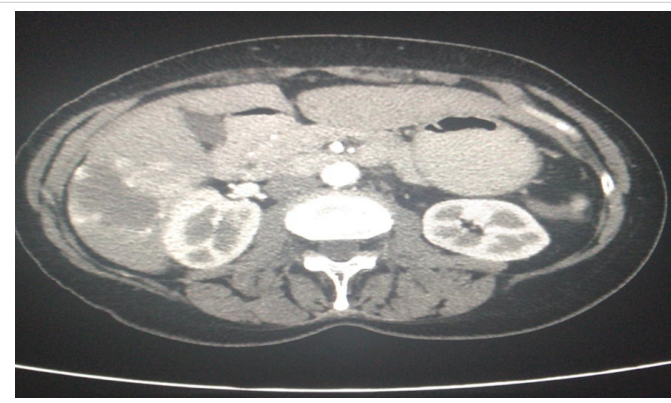

Figure 1: An axial abdominopelvic Computed Tomography (CT) scan demonstrates an incidental finding of giant hepatic hemangioma at the right lobe of the liver. CT scan was done due to suspicion of diverticulitis of the sigmoid colon.

\section{Literature Review}

Reviewing the current English literature reveals countless studies, mainly retrospective and limited to single center experience, who approved that expectant management for the typical hepatic hemangioma is safe. The primary outcomes assigned in these studies differ based on the purpose of the study in question, the key outcomes discussed are the development of new symptoms and the incidence of complications. The risk of complications during observation of this specific type of tumor is low and stands at less than $20 \%$. The risk for life threatening complications, such as spontaneous rupture, is extremely low at about $2 \%$. Nevertheless, studies regarding the safety of expectant management of the extremely large hepatic hemangioma (larger than $10 \mathrm{~cm}$ ), are lacking. Patients with this precise hepatic pathology were usually included as part of patients with giant liver hemangioma (larger than $5 \mathrm{~cm}$ ). Thus, Data regarding management of the extremely large hepatic hemangiomas is subpar at best.

While some surgeons believe that extremely large hemangiomas have greater potential for rupture, growth or internal bleeding, and thus, prophylactic resection should be offered; In other author's experience, size alone should be regarded as a poor predictor for future behavior of extremely large hepatic hemangiomas and should not be considered as an absolute indication.

The following is a review of the relevant studies. Upon conducting the aforementioned search algorithm seven studies reporting patients with extremely large hepatic hemangioma were found, these patients were part of a larger group of patients with giant hemangiomas. Out of these 7 studies, one study did not specify the different size of giant hemangioma, but nonetheless included due to its high number of patients.

All patients, 18 years or older, with hepatic hemangioma of $10 \mathrm{~cm}$ or larger were included. Articles examining hemangiomas smaller than $10 \mathrm{~cm}$ were excluded.

Studies were categorized into two groups; Supportive and opposed to the expectant management for the extremely large hepatic hemangiomas (larger than $10 \mathrm{~cm}$ ).

\section{Studies supporting expectant management}

Schnelldorfer reported a retrospective study over 20 years, including 289 patients with giant liver hemangiomas [14]. 233 patients were treated conservatively. 42 out of 233 $(18 \%)$ had extremely large hemangiomas (more than $10 \mathrm{~cm}$ ). The frequency of new onset of symptoms, such as chronic abdominal pain, and overall complications for patients with extremely large hemangiomas were not significantly greater than patients with hemangiomas smaller than $10 \mathrm{~cm}$ (14\% vs. $7 \%$ ) on a median follow up period of 11 years. 
Moreover, a study conducted by Yedibela [15], which included 246 patients, demonstrated that only $9 \%$ of patients in the conservative management group developed complications, with two fatal cases reported due to traumatic rupture of the hepatic hemangioma. In this specific study, sizes of hemangiomas were not reported and no correlation between size and complications were conducted.

Herman, et al. [16] published an article summarizing 14 year of experience managing hepatic hemangiomas. 249 patients were included, with 16 patients $(6.4 \%)$ having hepatic hemangioma larger than $10 \mathrm{~cm}$ in diameter. This group of patients suffered refractory pain more frequently than the group with the lower scaled hemangiomas. 8 patients (all with tumor size more than $14 \mathrm{~cm}$ ) out of 16 patients, underwent surgery (lobectomy or segmentectomy) mostly due to untreatable pain and all patients were free of pain on follow up. The other 8 patients with hemangiomas larger than $10 \mathrm{~cm}$ were observed and did not develop any complications or new symptoms.

The results of the previous studies support the expectant management for the extremely large liver hemangioma.

\section{Studies opposed to expectant management}

On the contrary, Erdogan, et al. [12] reported a retrospective study including 34 patients with liver hemangioma, of which 14 patients underwent resection. The mean size of the tumor for patients who underwent surgery was $10.3 \mathrm{~cm}$ and the indication for surgery was upper abdominal pain in most patients $(11 / 14)$. Only one patient had persistent abdominal pain following the resection of an $8 \mathrm{~cm}$ liver hemangioma. The findings of this study reflect that extremely large hemangiomas (larger than $10 \mathrm{~cm}$ ) are usually symptomatic and are advised to be treated by means of surgery.

Donati, et al. [17] published a review article concerning the risk for spontaneous rupture of liver hemangioma. 97 patients were described, of which 46 (47.4\%), mainly elderly patients (older than 40 ) with comorbidities suffered spontaneous rupture, and $52.6 \%$ suffered non spontaneous rupture, which was significantly more common in younger patients. The mean size of the ruptured tumor was $11.2 \mathrm{~cm}$, and the overall mortality rate was 35\%. The authors concluded that preventive surgery should be considered for lesions of at least $11-\mathrm{cm}$ in size.

In his study, Giuliante [18] reported the approach for liver hemangioma in a single center with 74 patients included. 40 patients (out of 74) underwent surgical management due to different indications such as abdominal pain, uncertain diagnosis, Kasabach-Merrit syndrome and tumor enlargement. It is worth mentioning that the average tumor size for the operated group was $11.9 \mathrm{~cm}$ vs. $6 \mathrm{~cm}$ in the conservative group. Again, Giuliante study supports the assumption that hepatic hemangiomas larger than $10 \mathrm{~cm}$ are indicated to be treated surgically due to several impending symptoms and complications.
Another study that builds on the same merit is the study by Zhang, et al. [19] which includes 86 patients with extremely large hepatic hemangiomas. 18 patients (21\%) were asymptomatic and incidentally discovered. These patients underwent prophylactic surgical resection due to different indications, including concern of future fatal complications (such as rupture) and due to patient's preference. Patients were not offered the opportunity of watchful waiting.

\section{Discussion}

Over the last several decades, a dramatic shift in the treatment of giant hepatic hemangioma has occurred, and it is mainly due to multiple studies published. The majority of these studies have approved that expectant management is safe and should be regarded as the gold standard treatment, moreover so in asymptomatic patients and in the absence of other indications for surgical management. Even in the presence of symptoms, which usually include upper abdominal pain or discomfort, a non-related pathology (such as peptic ulcer disease or cholelithiasis) should be excluded before attributing the symptoms to the liver hemangioma [20]. While the mainstay management for giant hepatic hemangioma is clear, the treatment of the extremely large liver hemangioma (larger than $10 \mathrm{~cm}$ ) is not well defined and is regarded as a gray zone for several hepatic surgeons. None of the reported studies have examined the safety of expectant management for the extremely large hepatic hemangiomas. Furthermore, the definition of giant hepatic hemangioma in the English literature consists of a wide array of tumor sizes comprising a range of 5 to $30 \mathrm{~cm}$ in tumor diameter. Thus, accumulating to the perplexity pertaining to the gold standard management of the extremely large hepatic hemangioma.

Whether or not the expectant management of extremely large hemangiomas of the liver is innocuous remains a debated topic, and surgeons are divided in their opinion regarding this subject, as has been mentioned previously.

This article review introduces conflicting data regarding the management of this precise type of tumor. Thus, treatment of these lesions should be patient specific depending on several factors (medical background, underlying chronic liver disease, presence of other underlying pathology), taking into consideration the associated symptoms and the risk of future complications, particularly rupture of the hemangioma, which has a high mortality rate of up to $35 \%$ [17].

\section{Conclusion}

In conclusion, as the authors have tried to demonstrate in this review, granted the expectant management of giant hepatic hemangioma is previously evidenced as safe, data regarding the treatment of extremely large hemangiomas of the liver (larger than $10 \mathrm{~cm}$ ) is lacking, and current papers discussing this topic are conflicting in their conclusions. Due to the higher probability of associated symptoms and 
indications for operation, a tumor scale higher than $10 \mathrm{~cm}$ should be regarded as a relative indication for surgical or non-surgical intervention (such as angiography), precisely in such cases where the remaining pathologies that may explain the symptoms have been excluded.

\section{References}

1. Maestroni U, Dinale F, Frattini A, Cortellini P. Ureteral hemangioma: A clinical case report. Acta Biomed. 2005; 76: 115-117.

PubMed: https://www.ncbi.nlm.nih.gov/pubmed/16350557

2. Tait N, Richardson AJ, Muguti G, Little JM. Hepatic cavernous haemangioma: A 10 year review. Aust N Z J Surg. 1992; 62: 521-524. PubMed: https://www.ncbi.nlm.nih.gov/pubmed/1610320

3. Choi BY, Nguyen $\mathrm{MH}$. The diagnosis and management of benign hepatic tumors. J Clin Gastroenterol. 2005; 39: 401-412. PubMed: https://www.ncbi.nlm.nih.gov/pubmed/15815209

4. Lise M, Feltrin G, Da Pian PP, Miotto D, Pilati PL, et al. Giant cavernous hemangioma: diagnosis and surgical strategies. World J Surg. 1992; 16: 516-20.

PubMed: https://www.ncbi.nlm.nih.gov/pubmed/1589990

5. Bioulac-Sage $P$, Laumonier $H$, Laurent $C$, Blanc JF, Balabaud C. Benign and malignant vascular tumors of the liver in adults. Semin Liver Dis. 2008; 28: 302-314.

PubMed: https://www.ncbi.nlm.nih.gov/pubmed/18814083

6. Ketchum WA, Lin-Hurtubise KM, Ochmanek E, Ishihara K, Rice RD. Management of Symptomatic Hepatic "Mega" Hemangioma. Hawaii J Med Public Health. 2019; 78: 128-131.

PubMed: https://www.ncbi.nlm.nih.gov/pubmed/30972235

7. Zhuang BW, Li W, Chen ZF, Cao CJ, Xie XY, et al. Multiple cavernous hemangiomas of the lung and liver mimicking metastasis: A case report and literature review. Medicine (Baltimore). 2018; 97: e13509. PubMed: https://www.ncbi.nlm.nih.gov/pubmed/30572451

8. Farges $\mathrm{O}$, Daradkeh $\mathrm{S}, \mathrm{Bismuth} \mathrm{H}$. Cavernous hemangiomas of the liver: are there any indications for resection? World J Surg. 1995; 19: 19-24. PubMed: https://www.ncbi.nlm.nih.gov/pubmed/7740805

9. Okano $H$, Shiraki $K$, Inoue $H$, Ito $T$, Yamanaka T, et al. Natural course of cavernous hepatic hemangioma. Oncol Rep. 2001; 8: 411-414. PubMed: https://www.ncbi.nlm.nih.gov/pubmed/11182065

10. Pietrabissa A, Giulianotti $P$, Campatelli A, Di Candio G, Farina F, et al. Management and follow-up of 78 giant haemangiomas of the liver. $\mathrm{Br}$
J Surg. 1996; 83: 915-918.

PubMed: https://www.ncbi.nlm.nih.gov/pubmed/8813773

11. Yoon SS, Charny CK, Fong $Y$, Jarnagin WR, Schwartz LH, et al Diagnosis, management, and outcomes of 115 patients with hepatic hemangioma. J Am Coll Surg. 2003; 197: 392-402.

PubMed: https://www.ncbi.nlm.nih.gov/pubmed/12946794

12. Erdogan GD, Busch OR, Van Delden OM, Bennink RJ, ten Kate FJ, et al. Management of liver hemangiomas according to size and symptoms. J Gastroenterol Hepatol. 2007; 22: 1953-1958.

PubMed: https://www.ncbi.nlm.nih.gov/pubmed/17914976

13. Hoekstra LT, Bieze M, Erdogan D, Roelofs JJ, Beuers UH, et al. Management of giant liver hemangiomas: An update. Expert Rev Gastroenterol Hepatol. 2013; 7: 263-268.

PubMed: https://www.ncbi.nlm.nih.gov/pubmed/23445235

14. Schnelldorfer T, Ware AL, Smoot R, Schleck CD, Harmsen WS, et al. Management of giant hemangioma of the liver: resection versus observation. J Am Coll Surg. 2010; 211: 724-730.

PubMed: https://www.ncbi.nlm.nih.gov/pubmed/20980175

15. Yedibela S, Alibek S, Muller V, Aydin U, Langheinrich $M$, et al. Management of Hemangioma of the Liver: Surgical Therapy or Observation? World J Surg. 2013; 37: 1303-1312. PubMed: https://www.ncbi.nlm.nih.gov/pubmed/23354918

16. Herman P, Costa MLV, Machado MAC, Pugliese V, D'Albuquerque LAC, et al. Management of Hepatic Hemangiomas: A 14-Year Experience. J Gastrointest Surg. 2005; 9: 853-859.

PubMed: https://www.ncbi.nlm.nih.gov/pubmed/15985244

17. Marcello D, Gregor S, Angelo D, Karl O. The risk of spontaneous rupture of liver hemangiomas: A critical review of the literature. $J$ Hepatobiliary Pancreat Sci. 2011; 18: 797-805.

PubMed: https://www.ncbi.nlm.nih.gov/pubmed/21796406

18. GiulianteF, ArditoF, Vellone M, Giordano M, Ranucci G, etal. Reappraisal of surgical indications and approach for liver hemangioma: singlecenter experience on 74 patients. Am J Surg. 2011; 201: 741-748. PubMed: https://www.ncbi.nlm.nih.gov/pubmed/20937504

19. Zhang W, Huang ZY, Ke CS, Wu C, Zhang ZW, et al. Surgical Treatment of Giant Liver Hemangioma Larger Than $10 \mathrm{~cm}$ : A Single Center's Experience with 86 Patients. Medicine (Baltimore). 2015; 94: e1420. PubMed: https://www.ncbi.nlm.nih.gov/pubmed/26313792

20. Bajenaru N, Balaban V, Savulescu F, Campeanu I, Patrascu T. Hepatic hemangioma- review. J Med Life. 2015; 8: 4-11. PubMed: https://www.ncbi.nlm.nih.gov/pubmed/26361504 